\title{
Optimization of the Bitumen Content of a Basaltic Semi-Granular Bituminous Concrete
}

\author{
Souleymane Mbengue1, Djibril Sow ${ }^{2}$, Ibrahima Khalil Cisse ${ }^{3}$ \\ ${ }^{1}$ Experimental Research and Study Center for Equipment, Ministry of Infrastructure, Thiès, Senegal \\ ${ }^{2}$ University Institute of Technology, University of Thiès, Thiès, Senegal \\ ${ }^{3}$ Polytechnic School of Thiès, Ministry of Higher Education, Research and Innovation, Thiès, Senegal \\ Email: souleymane00mbengue@yahoo.fr
}

How to cite this paper: Mbengue, S., Sow, D. and Cisse, I.K. (2018) Optimization of the Bitumen Content of a Basaltic Semi-Granular Bituminous Concrete. Open Journal of Civil Engineering, 8, 460-472. https://doi.org/10.4236/ojce.2018.84032

Received: August 16, 2018

Accepted: November 30, 2018

Published: December 3, 2018

Copyright (c) 2018 by authors and Scientific Research Publishing Inc. This work is licensed under the Creative Commons Attribution International License (CC BY 4.0).

http://creativecommons.org/licenses/by/4.0/

cc) (†) Open Access

\begin{abstract}
Various studies have been conducted in the past by researchers who have proposed diverse solutions to control the premature degradation noted on flexible pavements. It turns out that the binder content remains a parameter so far not mastered and its optimization remains an imperative to produce a quality mix capable of meeting the technical and economic requirements sought in a formulation study. This article mainly aimed to optimize the hydrocarbon binder content of a 0/14 granular class semi-granular bituminous concrete using the Marshall and Duriez method. In the first part of the study, the different constituents were characterized according to the standards in force. The second allowed to describe the methodology used to determine the mixture and calculated the theoretical binder content. A theoretical mixture, entering the reference zone was defined at first. Following the characterization of the mixture in the laboratory, the granulometry curve of the mixture was inserted into the reference zone. This mixture was then preserved for the rest of the study. Then, it was theoretically determined bitumen contents ranging from $5.13 \%$ to $5.75 \%$ for wealth modules ranging from $3.3 \%$ to $3.7 \%$. Thus, the Marshall method was used to characterize the performance of the mixture as a function of the binder content. The results obtained led to the selection of two grades of binders $5.13 \%$ and $5.28 \%$ for the study of water resistance using the Duriez method. On the basis of the results obtained on the Duriez test, the mixture with a binder content of $5.28 \%$ satisfies a good part of the criteria selected. This content corresponds to a wealth module of $3.4 \%$.
\end{abstract}

\section{Keywords}

Optimize, Binder, Bituminous Concrete, Spindle, Marshall, Duriez, Wealth Module 


\section{Introduction}

Bituminous concrete is by far the most used material in Senegal for the realization of the wearing course. Users must appreciate the quality of the contributive wearing course of their comfort and safety. Subjected to a growing traffic, the wearing courses must meet multiple requirements: surface characteristics, rolling noise reduction, Bituminous concretes are by far the most desired material and used in Senegal for the protection of the structure, service life, reduction of thicknesses and costs. As for the formulation of the coating, these requirements quickly become incompatible with each other [1]. Furthermore, to fully perform its function, the surface layer must also be able to withstand the forces of bending, compression and shear related to traffic. Indeed, the current traffic, of increasing intensity, always requires a higher degree of performance of asphalt mix.

Several researchers have been interested in the past years on the causes of premature deterioration of flexible pavements including ruts, faiençages, ressuages, cracks and have proposed multiple solutions through studies of asphalt concrete formulations. However, the binder content parameter is one of the major sources of the problem and deserves special attention. Existing studies have shown according to our documentary reviews and in practice shortcomings and limitations on its optimization which has dual interest in both technical and economic.

As a result, the formulation tests become more and more demanding in addition to the tests of the different constituents. Among these requirements, it will be necessary in this study to verify the evolution of the characteristics of the mixes, such as compactness, creep, stability and sensitivity to water depending on the binder content. For this, we will first use after identification of the various constituents, the Marshall test which is a method of determination of the content of vacuum and the mechanical characteristics of a bituminous mix. The process was developed by Bruce Marshall in 1939 [2]. Several standards frame the process such as the European standard EN 12697-34 [3]. Then the Duriez test which aims to determine, for a given compaction, the compressive strength of a test specimen weight and section was determined. It also makes it possible to define the resistance to water of the mix by the ratio of the compressive strengths after and before immersion of the specimen in a thermostatic water bath. The test is described according to standard NF P 98-251-1 of September 2002 [4] on hot hydrocarbon mixtures. Finally an optimal binder content will be deduced.

\section{Experimentation}

\subsection{Materials}

The materials used are mainly aggregates and bitumen. The aggregates come from the Diack quarry in the region of Thiès located $70 \mathrm{~km}$ from Dakar in Senegal. They are collected by not good care and received at the laboratory of the Experimental Center for Research and Studies for Equipment of Senegal (CEREEQ). 
Bitumen is marketed in Senegal by EUROPEAN RAILROAD ESTABLISHED SERVICES (ERES S.A).

\subsubsection{Aggregates}

They have been listed as follows:

Basalt 8/14.

Basalt 3/8.

Basalt $0 / 3$.

Table 1 gives the results obtained on the granulometric analysis, the specific gravity and the sand equivalent of the aggregates used according to the standards NF P 94056 [5], NF EN 1097-6 [6], EN 933-8 [7]. It turns out that from the point of view granularity (\% refusal to $\mathrm{D}$ for chippings, $\%$ passing to $\mathrm{d}$ for gravel, $\%$ refusal to D for sands), except class $3 / 8$ which slightly exceeds the value limit $(15.26 \%>15 \%)$, the basalt meets the specifications of standard NF EN 933-1 May 2012 [8]. This reflects an acceptable crushing of the material. On the basis of the data obtained on the particle size analysis, the curves of Figure 1 are established.

Table 1. Particle size analysis, specific gravity and sand equivalent.

\begin{tabular}{|c|c|c|c|c|}
\hline \multirow{2}{*}{ AFNOR sieve Module } & \multicolumn{4}{|c|}{$\%$ passing in the sieves } \\
\hline & Opening $(\mathrm{mm})$ & Basalt $0 / 3$ & Basalt 3/8 & Basalt $8 / 14$ \\
\hline 44 & 20 & & & \\
\hline 43 & 16 & & & 99.02 \\
\hline 42 & 14 & & & 94.68 \\
\hline 41 & 12.5 & & & 84.74 \\
\hline 40 & 10 & & 97.56 & 23.7 \\
\hline 39 & 8 & & 84.74 & 8.28 \\
\hline 38 & 6.3 & & 57.34 & 1.7 \\
\hline 37 & 5 & & 34.26 & 0.74 \\
\hline 35 & 4 & & 15 & 0.4 \\
\hline 32 & 3.15 & 98.6 & 2.34 & 0.36 \\
\hline 29 & 2.5 & 94 & 0.64 & \\
\hline 26 & 2 & 61.4 & 0.48 & \\
\hline 23 & 1.25 & 46.2 & & \\
\hline \multirow[t]{5}{*}{20} & 0.63 & 32.2 & & \\
\hline & 0.5 & 30 & & \\
\hline & 0.315 & 25.4 & & \\
\hline & 0.16 & & & \\
\hline & 0.08 & 15.6 & & \\
\hline Specific weight in $\mathrm{T} / \mathrm{m}^{3}$ & & 2.793 & 2.915 & 2.932 \\
\hline Sand equivalent (\%) & & & 61 & \\
\hline
\end{tabular}


The micro-Deval test allowed in this study to determine the micro-Deval coefficient which gives information on the resistance to the wear by the mutual friction of the elements of a granulate. It is carried out according to the European standard EN 1097-1 [9]. The values obtained on the Diack 8/14 and $3 / 8$ basalt, respectively, show good resistance to wear and stripping. All values are below the specified thresholds ( $\leq 20$ for $\mathrm{T}>\mathrm{T} 2$ ); $\leq 25$ for $\mathrm{T}<\mathrm{T} 2$ ) according to the New Pavement Structures Catalog and SENEGAL Pavement Design Guide; Dakar (Senegal), provisional version 2-202 pages [10].

Table 2 provides information on the values obtained.

The hardness of Diack's basaltic aggregates is appreciated by the Los Angeles trial which aims to measure the resistance to shock fragmentation of the elements of a sample of aggregates. It is carried out according to the European standard EN 1097-2 [11]. The results of the study show that Diack's basalt has excellent intrinsic characteristics for the preparation of bituminous mixes in terms of hardness according to the AGEROUTE catalog (LA $<25, \mathrm{MDE}<20$, $\mathrm{LA}+\mathrm{MDE}<35)$. The results obtained are shown in Table 3. The shape of the aggregates is characterized by the flattening coefficient according to the European standard EN 933-10 [12]. The values obtained respectively on basalt $8 / 14$ and $3 / 8$ attest to good manufacturing characteristics. All values are below the specified thresholds ( $\leq 20$ for $\mathrm{T}>\mathrm{T} 2$ ); $\leq 25$ for $\mathrm{T}<\mathrm{T} 2$ ) according to the AGEROUTE Senegal catalog. Table 4 and Table 5 show the values found.

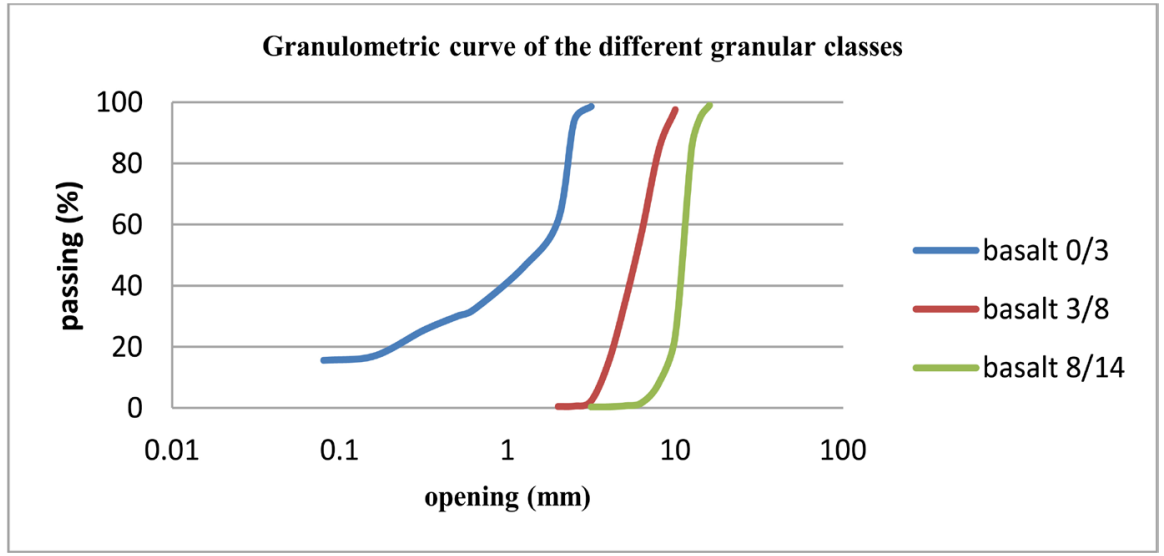

Figure 1. Granulometric curve of the different granular classes.

Table 2. Micro deval trials.

\begin{tabular}{ccccccc}
\hline $\begin{array}{c}\text { Nature } \\
\text { of the sample }\end{array}$ & $\begin{array}{c}\text { Granular } \\
\text { class }\end{array}$ & $\begin{array}{c}\text { Initial weight } \\
\text { P0 (g) }\end{array}$ & $\begin{array}{c}\text { Weight after } \\
\text { wash P1 }(\mathrm{g})\end{array}$ & $\begin{array}{c}\text { Weight of element } \\
<1.6 \mathrm{~mm} \mathrm{P2}(\mathrm{g})\end{array}$ & $\begin{array}{c}\text { MDE } \\
\text { Coefficient } \\
(\%)\end{array}$ & $\begin{array}{c}\text { MDE } \\
\text { Average } \\
(\%)\end{array}$ \\
\hline \multirow{2}{*}{ Basalt 8/14 } & $10 / 14$ & 500 & 444 & 56 & 11.2 & 11.10 \\
& & 445 & 55 & 11.0 & \\
Basalt 3/8 & $4 / 6.3$ & 500 & 438 & 62 & 12.4 & 12.60 \\
\hline
\end{tabular}


Table 3. Los angeles trials.

\begin{tabular}{cccccc}
\hline $\begin{array}{c}\text { Nature } \\
\text { of the sample }\end{array}$ & Granular class & $\begin{array}{c}\text { Initial } \\
\text { weight P0 (g) }\end{array}$ & $\begin{array}{c}\text { Weight after } \\
\text { wash P1 (g) }\end{array}$ & $\begin{array}{c}\text { Weight of element } \\
<1.6 \mathrm{~mm} \mathrm{P2} \mathrm{(g)}\end{array}$ & LA coefficient (\%) \\
\hline Basalt 8/14 & $10 / 14$ & 5000 & 4325 & 675 & 13.5 \\
Basalt 3/8 & $4 / 6,3$ & 5000 & 4298 & 702 & 14.0 \\
\hline
\end{tabular}

Table 4. Gravel flattening tests 8/14.

\begin{tabular}{|c|c|c|c|}
\hline Sieving on sieves & & Screening on a grid & \\
\hline Granular class d/D (mm) & $\mathrm{Mg}(\mathrm{g})$ & Grids spacing $(\mathrm{mm})$ & Passing Mei (g) \\
\hline $31.5 / 40$ & & 20 & \\
\hline $25 / 31.5$ & & 16 & \\
\hline $20 / 25$ & & 12.5 & \\
\hline $16 / 20$ & 65 & 10 & 13 \\
\hline $12.5 / 16$ & 525 & 8 & 50 \\
\hline $10 / 12.5$ & 3207 & 6.3 & 507 \\
\hline $8 / 10$ & 804 & 5 & 194 \\
\hline $6.3 / 8$ & 333 & 4 & 74 \\
\hline $5 / 6.3$ & 38 & 3.15 & 6 \\
\hline $4 / 5$ & 12 & 2.5 & 1 \\
\hline $\mathrm{M}=\Sigma \mathrm{Mgi}$ & 4984 & $\mathrm{M}=\Sigma \mathrm{Mei}$ & 845 \\
\hline \multirow[t]{2}{*}{$\mathrm{M}_{0}$} & 4996 & & \\
\hline & A (\%) & 16.95 & \\
\hline
\end{tabular}

Table 5. Gravel flattening tests 3/8.

\begin{tabular}{|c|c|c|c|}
\hline Sieving on sieves & & Screening on a grid & \\
\hline Granular class d/D (mm) & $\operatorname{Mg}(g)$ & Grids spacing (mm) & Passing Mei (g) \\
\hline $31.5 / 40$ & & 20 & \\
\hline $25 / 31.5$ & & 16 & \\
\hline $20 / 25$ & & 12.5 & \\
\hline $16 / 20$ & & 10 & \\
\hline $12.5 / 16$ & & 8 & \\
\hline $10 / 12.5$ & 58 & 6.3 & 19 \\
\hline $8 / 10$ & 230 & 5 & 46 \\
\hline $6.3 / 8$ & 726 & 4 & 167 \\
\hline $5 / 6.3$ & 541 & 3.15 & 50 \\
\hline $4 / 5$ & 800 & 2.5 & 170 \\
\hline $\mathrm{M}=\Sigma \mathrm{Mgi}$ & 2355 & $\mathrm{M}=\Sigma \mathrm{Mei}$ & 452 \\
\hline \multirow[t]{2}{*}{$\mathrm{M}_{0}$} & 2361 & & \\
\hline & $\mathrm{A}(\%)$ & 19.19 & \\
\hline
\end{tabular}




\subsubsection{Bitumen}

As part of this research, the bitumen of the company ERES SA is used. It is characterized by the penetration test on bitumen (EN 1426) [13] and the ball and ring softening point test (EN 1427) [14].

The penetration test made it possible to characterize the consistency of the bitumen, its hardness and rigidity at ambient temperature. The values obtained in this study are shown in Table 6. It reveals 35/50 grade bitumen.

The softening test evaluated the consistency of bitumen at high service temperature. Table 7 provides acceptable results for this type of study.

Table 6. Penetration test.

\begin{tabular}{cccc}
\hline Trial number & Number of measures & Read values & Average \\
& $1^{\text {st }}$ measure & 45 & 44 \\
$1^{\text {st }}$ try & $2^{\text {nd }}$ measure & 43 & 43 \\
& $3^{\text {rd }}$ measure & 43 \\
\hline
\end{tabular}

Table 7. Ball and ring softening test.

\begin{tabular}{|c|c|c|c|}
\hline \multicolumn{4}{|c|}{ Starting temperature: $23.5^{\circ} \mathrm{C}$} \\
\hline Reading & time & Temperature & Average \\
\hline & 1 & 23.8 & \\
\hline & 2 & 24.2 & \\
\hline & 3 & 25.6 & \\
\hline & 4 & 27 & \\
\hline & 5 & 28.6 & \\
\hline & 6 & 29.8 & \\
\hline & 7 & 30.9 & \\
\hline & 8 & 32.0 & \\
\hline & 9 & 33.4 & \\
\hline & 10 & 34.6 & \\
\hline & 11 & 36 & \\
\hline & 12 & 37.8 & \\
\hline & 13 & 39.1 & \\
\hline & 14 & 40.7 & \\
\hline & 15 & 41.7 & \\
\hline & 16 & 43.0 & \\
\hline & 17 & 44.6 & \\
\hline & 18 & 45.8 & \\
\hline & 19 & 47.0 & \\
\hline & 20 & 48.8 & \\
\hline & 21 & 50.2 & \\
\hline & 22 & 51.4 & \\
\hline & 23 & 52.7 & \\
\hline Softening & $23 ' 25^{\prime \prime}$ & 53.4 & \\
\hline Softening & $24^{\prime} 00^{\prime \prime}$ & 55 & 54.2 \\
\hline
\end{tabular}




\subsubsection{The Mixture}

In this study, the Marshall method which is an empirical method is used in. It comprises both a formulation test part and a developed part of the formulation by tests for determining the performance of the mixture. From the granulometric curves of the different granular classes, a mixture is selected whose curve is inscribed within the limits of the spindle defined for a bituminous concrete 0/14. Figure 2 gives the granulometric curve of the mixture which fits into the spindle. Table 8 shows the corresponding granular composition. Then the binder content TLext is determined according to this formula.

$$
\text { TLext }=100 \times \frac{M_{b}}{M_{G S}}[15] .
$$

With $M_{b}=$ mass of bitumen.

$M_{G S}=$ mass of dry aggregates.

The binder content is related to the richness modulus and the specific surface by the following equation:

$$
\begin{gathered}
\text { TLext }=K \times \alpha \times \sqrt[5]{\varepsilon} \\
100^{\varepsilon}=0.25 G+2.3 S+12 s+150 f
\end{gathered}
$$

With:

$\varepsilon:$ Specific surface.

$G$ : Element ratio greater than $6.3 \mathrm{~mm}$.

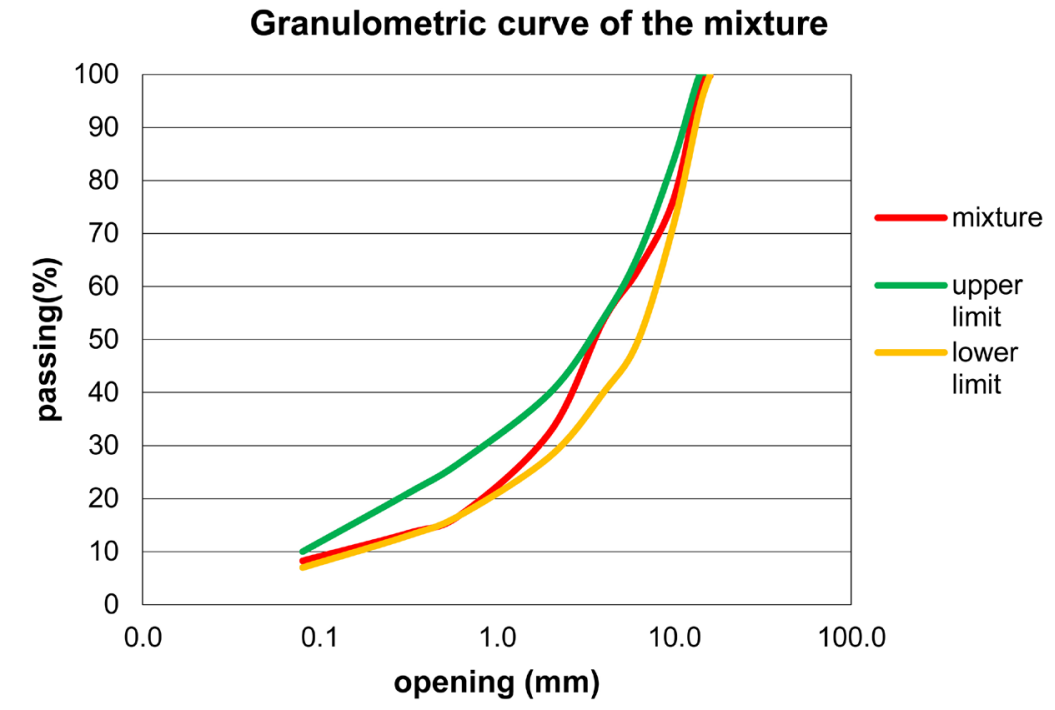

Figure 2. Granulometric curve of the mixture.

Table 8. Granular composition of the theoretical mixture and variation mitumen content.

\begin{tabular}{cc}
\hline Granular composition & Variation bitumen content (\%) \\
$30 \%$ de $8 / 14$ & \\
$17 \%$ de $3 / 8$ & $5.13-5.28-5.44-5.59-5.75$ \\
$53 \%$ de $0 / 3$ & \\
\hline
\end{tabular}


$S$ : Proportion of elements between $6.3 \mathrm{~mm}$ and $0.315 \mathrm{~mm}$.

$S$ : proportion of elements between $0.315 \mathrm{~mm}$ and $0.080 \mathrm{~mm}$.

f. proportion of elements less than $0.080 \mathrm{~mm}$.

$\alpha$ : correction coefficient relating to the density of the aggregates.

$$
\alpha=2.65 / \rho_{G}
$$

With $\rho_{G}$ the actual density of the aggregates in $\mathrm{g} / \mathrm{cm}^{3}$.

\section{Method}

The method used is based on the methodological principle of the Marshall and Duriez test.

\subsection{Marshall}

The Marshall tests are carried out according to standard NF EN 12697-34 of August 2012. The purpose of this test is to determine the mechanical characteristics (stability, creep) as well as the percentage of voids of the compacted bituminous mixture under standardized conditions. Five sets of specimens are made for mixing with binder contents ranging from 5.13 to 5.75 .

Since the granular mixture gave satisfactory results with an insertion of its granularity in the reference zone, it is admissible and chosen for the rest of the study. This phase is followed by a determination of theoretical optimal bitumen contents. The results obtained lead us to draw up a Marshall test program with variable binding contents.

\subsection{Duriez}

The principle of the Duriez test, according to standard NF P 98-251-1, is manufactured by double-acting static compaction, some of which are subjected to the compression test after storage at $18^{\circ} \mathrm{C}$ under defined conditions ( in the air and in the water). Others are intended for the measurement of the density by hydrostatic weighing to calculate the compactness. For the mixture, 07 specimens were made and distributed as follows:

02 tested in simple compression after 24 hours;

02 tested in simple compression after 07 days of storage in air at $18^{\circ} \mathrm{C}$;

02 tested in simple compression after 07 days of storage in water $18^{\circ} \mathrm{C}$.

One reserved to determine the compactness of the mixture. For each parameter, a figure is presented with the values obtained and the limit values generally retained by the technical prescriptions.

\section{Results and Discussions}

The difficulty of formulating the surface layers stems from the fact that the qualities are often contradictory. The bituminous concretes of the LCPC-SETRA formulas are currently limited to $0 / 10$ and $0 / 14$ semi-graded concretes, characterized by high thicknesses, as well as excellent resistance to permanent 
deformation [16]. Table 9 gives some technical specifications of $0 / 10$ and $0 / 14$ semi-granular bituminous concrete according to standard NF EN 13108-1 [17]. Table 10 gives specifications for the Marshall and Duriez test.

The evolution curve of the compactness for each mixture is shown in Figure 3.

It is found that compared to the established limit values, the binder content of

Table 9. Specifications of semi-grained bituminous concrete.

\begin{tabular}{|c|c|c|c|}
\hline Characteristics & Standards & BBSG 0/10 & BBSG 0/14 \\
\hline $\begin{array}{c}\text { Percentage of voids } \\
\text { Vmin } \% \text { - Vmax } \% \\
\text { (méthode compacteur giratoire) }\end{array}$ & NF EN 12687-31 & $\begin{array}{l}\text { Vmin } 5 \text { Vmax } 10 \\
\text { (60 girations) }\end{array}$ & $\begin{array}{l}\text { Vmin4 } \mathrm{Vmax} 9 \\
(80 \text { girations })\end{array}$ \\
\hline $\begin{array}{c}\text { Sensitivity to water } \\
\text { Report } \\
\text { i/C\% (méthode compression) }\end{array}$ & NF EN 12697-12 & \multicolumn{2}{|c|}{$\geq 70 \%$} \\
\hline $\begin{array}{l}\text { Resistance to deformation } \\
\text { \% empty test-tube Vi-Vs (large model in the air) }\end{array}$ & NF EN 12697-22 & \multicolumn{2}{|c|}{$\begin{array}{c}\leq 7.5 \%(\text { class } 2) \\
\leq 5 \%(\text { class } 3) \\
\text { à } 60^{\circ} \mathrm{C} \text { et } 30000 \text { cycles } \\
\mathrm{Vi}=5 \%-\mathrm{Vs}=8 \%\end{array}$} \\
\hline $\begin{array}{l}\text { Minimum stiffness modulus } \\
\qquad(\mathrm{MPa}) \\
\%\end{array}$ & $\begin{array}{l}\text { NF EN 12697-26 } \\
\text { annexe A ou E }\end{array}$ & $\begin{array}{r}\mathrm{E} \geq 5500 \mathrm{M} \\
\mathrm{E} \geq 7000 \mathrm{MPa} \\
\text { à } 15^{\circ} \mathrm{C} \text { } \\
\mathrm{E} \geq 1512 \mathrm{M} \\
\mathrm{E} \geq 1896 \mathrm{MPa} \\
\mathrm{A} 34^{\circ} \mathrm{C} \\
\mathrm{Vi}=5 \%\end{array}$ & $\begin{array}{l}\mathrm{Pa} \text { (class } 1) \\
\text { (class } 2 \text { et } 3 \text { ) } \\
10 \mathrm{~Hz}, \\
\mathrm{~Pa} \text { (class } 1) \\
\text { (class } 2 \text { et } 3 \text { ) } \\
\mathrm{t} 20 \mathrm{~Hz}, \\
\mathrm{Vs}=8 \%\end{array}$ \\
\hline $\begin{array}{c}\text { Fatigue } \\
\% \text { des vides éprouvettes Vi-Vs }\end{array}$ & $\begin{array}{l}\text { NF EN } 12697-24 \\
\text { annex A }\end{array}$ & \multicolumn{2}{|c|}{$\begin{array}{c}\varepsilon 6 \geq 100.10-6 \text { à } 10^{\circ} \mathrm{C} 25 \mathrm{~Hz} \\
\mathrm{Vi}=5 \%-\mathrm{Vs}=8 \%\end{array}$} \\
\hline Binder content ( $\%$ int) & NF EN 12697-1 & $\mathrm{TL} \min 5.2$ & $\mathrm{TL} \min 5.0$ \\
\hline Module of wealth & - & $\mathrm{K}>3.4$ & $\mathrm{~K}>3.2$ \\
\hline
\end{tabular}

Table 10. Specifications for the Marshall and Duriez test.

\begin{tabular}{cc}
\hline Type of asphalt & Asphaltic concrete \\
\hline 50 shot Marshall trial & \\
compactness & 94 à $97 \%$ \\
creep & $<4 \mathrm{~mm}$ \\
Marshall stability at $60^{\circ} \mathrm{C}$ & $\geq$ à $1000 \mathrm{kgf}$ \\
Duriez trial & \\
compactness & \\
R'c/Rc & \\
Water absorption rate $96 \%$ \\
\hline
\end{tabular}


$5.44 \%$ which gives a compactness of 97.32 is outside the acceptability range. On the other hand all the other contents of binding confer densities which vary between 94.98 to $96.85 \%$ therefore fall within the admissible range. The contents with which good compacities are obtained are then selected.

The stability evolution curves is shown in Figure 4. Concerning the Marshall stability, all the bitumen contents provide a mechanical resistance higher than the threshold value which is $1000 \mathrm{Kgf}$. However, Marshall stability is not an absolute measure of resistance [18]. In other words, the Marshall test gives no indication of the resistance to deformation of a coating but serves as a control of the regularity of asphalt pavement production [19].

The evolution of Marshall creep curves is shown in Figure 5. By observing the evolution of the fluings, we notice that all the contents fulfill the fixed conditions.

EVOLUTION OF MARSHALL COMPACITY BASED ON BITUMEN CONTENT

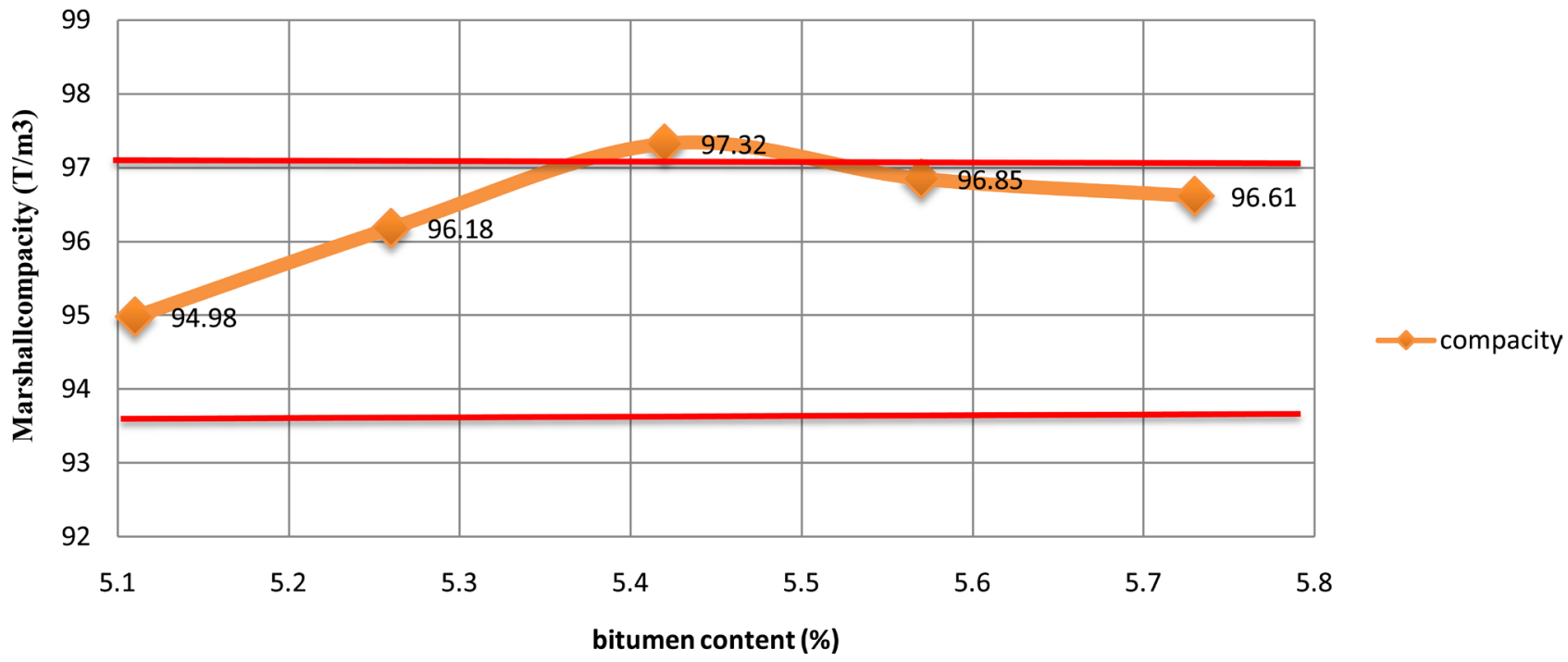

Figure 3. Evolution of the Marshall compactness according to the bitumen content.

EVOLUTION OF MARSHALL STABILITY IN RELATION TO BITUMEN CONTENT

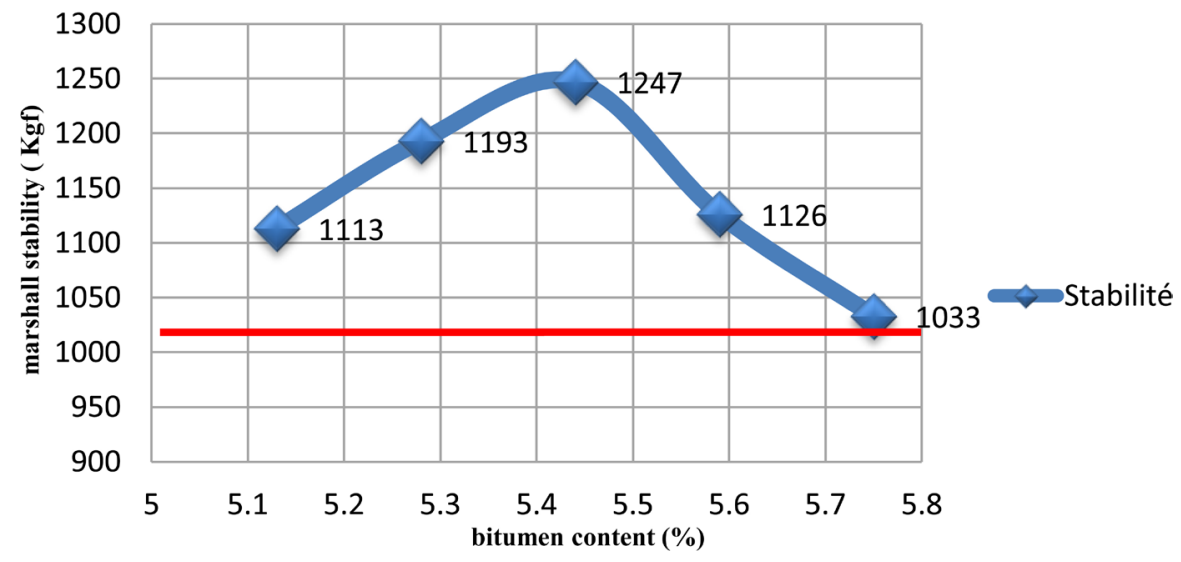

Figure 4. Evolution of Marshall stability as a function of bitumen content. 
Correct Marshall fluings were obtained for all preselected grades on the basis of compactness and stability. Following the analysis of the results obtained on the Marshall test, an evaluation of the water sensitivity (Duriez test) is used with the bitumen contents of $5.13 \%$ and $5.28 \%$ which are the values of the content of the binder filling. at best all the criteria.

Figure 6 gives the evolution of Duriez compactness according to the bitumen contents selected after the Marshall test. It shows the existence of a range of acceptability of compactness Duriez which is between $92 \%$ and $96 \%$.

Following the analysis of the results, it is found that only the binder content of $5.28 \%$ gives a compactness of $93.6 \%$ which falls within the range of acceptability. The bi-tume content of $5.13 \%$ provides a $91.8 \%$ Duriez compactness that deviates from the allowable threshold.

Figure 7 shows the evolution of the ratio between the compressive strength of specimens kept for 7 days in water at $18^{\circ} \mathrm{C}$ and those kept in air at the same temperature depending on the selected bitumen contents following the Marshall test. A limit value of 0.7 represents the minimum value that this report must

\section{EVOLUTION OF MARSHALL CREEP AS A FUNCTION OF BITUMEN CONTENT}

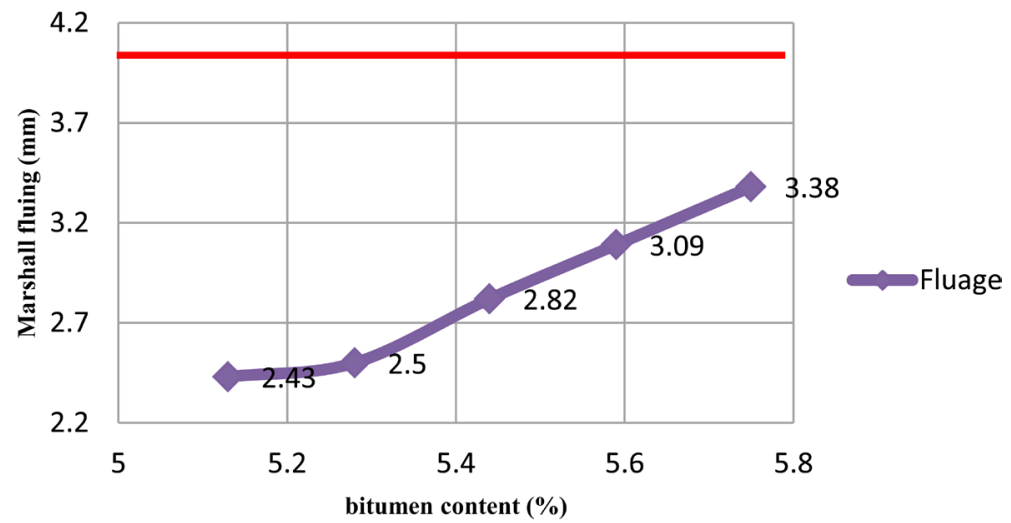

Figure 5. Evolution of Marshall creep as a function of bitumen content.

EVOLUTION OF COMPACITY DURIEZ DEPENDING ON THE BITUMEN CONTENT

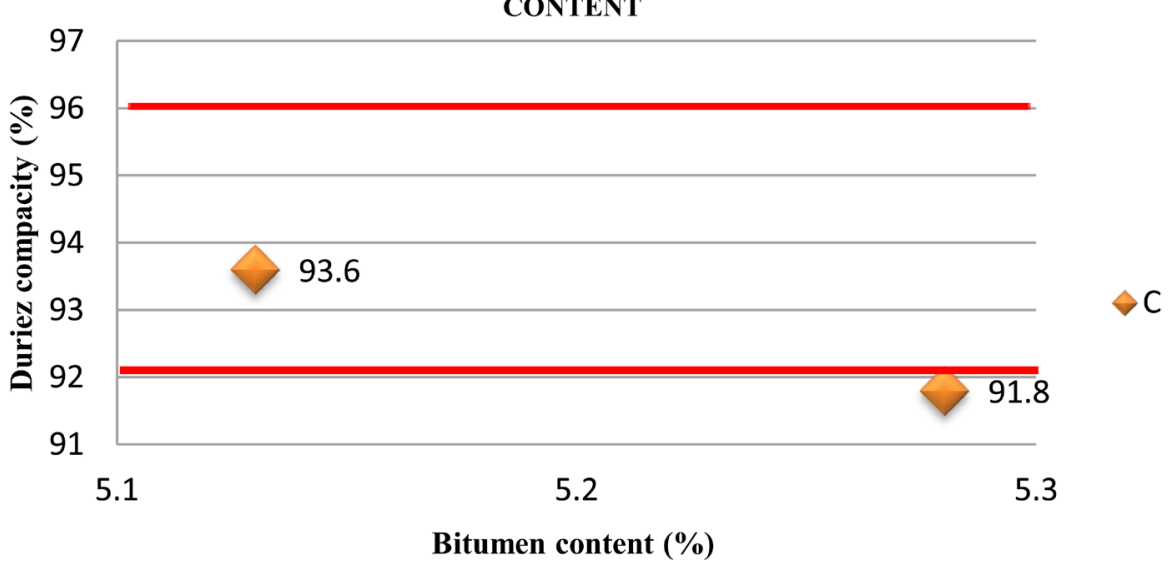

Figure 6. Evolution of the compactness Last according to the bitumen content. 
EVOLUTION OF IMMERSION / COMPRESSION RATIO BASED ON BITUMEN CONTENT

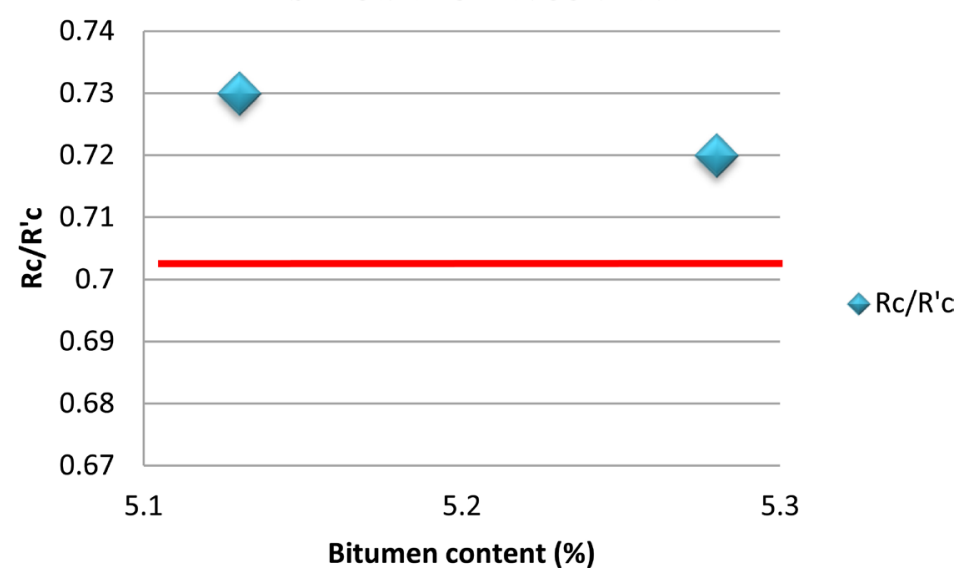

Figure 7. Evolution of the immersion/compression ratio according to the bitumen content.

provide to be accepted. Following the analysis of the results obtained, the mixture has $\mathrm{r} / \mathrm{R}$ ratios of 0.73 and 0.72 greater than the minimum required value of 0.70 for respective binder contents of $5.13 \%$ and $5.28 \%$.

\section{Conclusions}

This study shows that the optimum binder content of $5.28 \%$ gives the mixture the best performance which best meets the requirements of the technical requirements. The Marshall and Duriez trials have made it possible to characterize the mixture to achieve such a result.

This optimization study of the bitumen content of a semi-granular bituminous mix offers both technical and economic interest and pushes the limits of research in this field.

However, this study needs to be supplemented by higher level formulation tests such as the gyratory shear press test, the rutting test, the fatigue and module test to better understand the mechanical behavior of the bituminous mixture. semi-granular basaltic.

\section{Conflicts of Interest}

The authors declare no conflicts of interest regarding the publication of this paper.

\section{References}

[1] Soliman, S., Eckmann, B., Bakowski, S. and Detraux, F. (2009) Wearing Courses. Vol. 7, 20 th Belgian Road Congress, Brussels, 28-30 September 2005.

[2] Lavin, P. (2003) Asphalt Pavements. Spon Press, London, 142.

[3] (2012) Bituminous Mixtures-Test Methods for Hydrocarbon. NF EN 12697-34.

[4] (2002) Tests Relating to Roadways-STATIC Tests on Hydrocar. NF P98-251-1.

[5] Analysis Sieving Granulometry. NF P 94056. 
[6] Test to Determine the Specific Gravity of the Aggregates. NF EN 1097.

[7] Test to Determine the Equivalent Value of Sand. EN 933-8.

[8] (2012) Tests to Determine the Geometrical Characteristics of Ag. NF EN 933-1.

[9] Micro Deval Test to Determine the Resistance to Wear. EN 1097-1.

[10] Catalog of New Pavement Structures and Design Guide for Pavements in SENEGAL.

[11] Los Angeles Trial to Determine Resistance to Fragmentation. EN 1097-2.

[12] Flattening Test to Determine the Shape of Aggregates. EN 933-10.

[13] Bitumen Penetration Test. EN 1426.

[14] Ring and Ball Softening Test. EN 1427.

[15] Bituminous Mixes (USIRF), Volume 1, December 2001, 229 p.

[16] Bonnot, J. (1977) Road Uses of Bitumen. rev gen roads aerodr, 536.

[17] NF EN 13108-1. Abuminous Mixture-Specification of Materials-Part 1: Bituminous.

[18] Metcalf, C.T. (1959) Use of Marshall Stability Test in Asphalt Paving Mix Design.

[19] Marshall Trial (2017) Wikipedia, the Free Encyclopedia. 16:47. 